\title{
CLASSES PADRO̊ES DE MATURIDADE DA FIBRA DO ALGODOEIRO NA DETERMINAÇÃO PELO MÉTODO DO FIBRÓGRAFO (')
}

\author{
MILTON GERALDO FUZATTO $\left({ }^{2}\right)$, IMRE LAJOS GRIDI-PAPP $\left({ }^{2}\right)$, \\ NELSON PAULIERI SABINO $\left({ }^{3,4}\right)$, JÚLIO ISAO KONDO $\left({ }^{3}, 4\right)$ \\ e EDERALDO JOSÊ CHIAVEGATO $\left({ }^{2,4}\right.$ )
}

\begin{abstract}
RESUMO
A partir de evidências de que padrões internacionais de avaliação da maturidade da fibra do algodoeiro, referentes à determinação pelo processo da soda cáustica a 18\%, nâo se mostravam adequados para avaliar essa característica, quando a determinaçâo é feita pelo método do Fibrógrafo, realizou-se um estudo visando definir uma escala de classificação específica para este método. Uma curva de distribuição normal foi ajustada aos dados das 59 amostras de algodão empregadas no trabalho original, que propôs o método, e nela foram definidos os percentis $10,30,70 \mathrm{e}$ 90 para corresponderem aos limites das classes "muito baixa", "baixa", "média", "alta" e "muito alta" de maturidade da fibra. Em conseqüência, foram encontrados os valores $14,59,13,40,11,79$ e 10,67, expressos segundo os índices obtidos no Fibrógrafo, para constituírem as separatrizes das referidas classes de maturidade. Exprimindo-se os resultados em termos de porcentagens de fibras maturas, em equivalência ao que seria obtido com o processo da soda cáustica, os mencionados limites correspondem, aproximadamente, a $45,52,63$ e $72 \%$.
\end{abstract}

Termos de indexação: algodão; fỉra; maturidade; Fỉbrógrafo; classificação.

\footnotetext{
(1) Recebido para publicaçāo em 28 de maio de 1984.

( ${ }^{2}$ ) Seção de Algodão, Instituto Agronômico (IAC), Caixa Postal, 2813100 - Campinas (SP).

( $\left.{ }^{3}\right)$ Seção de Tecnologia de Fibras, IAC.

$\left({ }^{4}\right)$ Com bolsa de suplementação do CNPq.
} 


\section{INTRODUÇÃO}

SABINO et alii (1971) mostraram a possibilidade de determinar a maturidade da fibra do algodoeiro por meio do Fibrógrafo, aparetho normalmente utilizado para medir o comprimento das fibras. Em trabalhos subseqüentes, GRIDI-PAPP \& SABINO (1972) e SABINO et alii (1980) apresentaram os fundamentos do processo, possibilitando sua introdução na rotina das análises realizadas pela Seção de Tecnologia de Fibras, do Instituto Agronômico.

Por esse método são obtidos, a partir de leituras no aparelho e pesagens das amostras, índices representativos da maturidade, os quais são posteriormente expressos em porcentagens de fibras maduras, valores esses correspondentes aos que seriam obtidos se as determinações fossem feitas pelo método da soda cáustica a $18 \%$. Essa transformação está baseada em correlação verificada no trabalho que estabeleceu o método do Fibrógrafo (GRIDI-PAPP \& SABINO, 1972), uma vez que nesse estudo algodões produzidos por diferentes materiais genéticos tiveram a maturidade determinada pelos dois processos.

Todavia, implantado o método, verificou-se logo que as determinações, inclusive as feitas em material sabidamente de boa maturidade, apresentavam quase sempre valores baix os para essa característica, quando classificados pelos padrões internacionais adotados para o método da soda cáustica (LORD, 1961). Se em trabalhos experimentais, nos quais as comparações demandam apenas números relativos, tal fato não apresentava grandes problemas, o mesmo não se podia afirmar quando as avaliações eram feitas em valores absolutos. Nesses casos, de acordo com os padrões internacionais, os algodões produzidos no Brasil, quaisquer que fossem as variedades ou a região de cultivo, apresentavam, com raras exceções, fibras imaturas.

O presente trabalho visou solucionar o problema, mediante o estabelecimento de padrões de maturidade específicos para o método em apreço.

\section{MATERIAL E MÉTODOS}

Para o presente estudo, foram utilizados os dados obtidos no trabalho de GRIDI-PAPP \& SABINO (1972) compreendendo determinações de maturidade da fibra realizadas em 59 amostras de algodão. Tais amostras representavam ampla faixa de variação para a referida característica da fibra, graças à diversidade do material genético de que provinham e das 
condições em que as plantas foram cultivadas. A partir desses dados, adotou-se o seguinte procedimento:

dados;

a) verificação do tipo de distribuição de freqüências sugerido pelos

b) ajuste aos dados de curva teórica de distribuição de freqüências e teste estatístico de sua adequação;

c) definição de percentis, na curva ajustada, correspondentes aos limites das classes muito baixa, baixa, média, alta e muito alta, de maturidade da fibra;

d) Cálculo dos valores de maturidade correspondentes aos percentis fixados e elaboração dos limites de classes.

Todos os cálculos foram feitos com os valores de maturidade dados pela expressão $\mathrm{L}^{2} / \mathbf{1 0}^{6} \mathrm{p}$, onde $\mathrm{L}$ representa o número de fibras contidas no pente do aparelho, por ocasião da determinação, e p, o peso delas.

Determinados os limites das classes de maturidade, os valores correspondentes foram transformados em porcentagens de fibras maduras, a fim de apresentar em termos mais concretos a escala de classificação proposta.

\section{RESULTADOS E DISCUSSÃO}

No quadro 1, encontra-se a distribuição de freqüencias dos valores de maturidade da fibra utilizados no estudo.

Efetuados os cálculos, foi ajustada aos dados uma curva de distribuição normal com média $=12,57$ e desvio-padrão $=1,66$. A adequação do ajuste ficou evidenciada pelo valor obtido no teste qui-quadrado $(4 ; 57)$, bem abaixo do exigido para a significância ao nível de $5 \%(11,07)$. O histograma de freqüências e a curva ajustada aos dados encontram-se na figura 1.

A seguir, para determinar os limites de cinco classes de maturidade da fibra, foram escolhidos os percentis $10,30,70$ e 90, na curva de distribuição. A esses percentis corresponderam os valores $14,59,13,40,11,79$ e 10,67 de maturidade, expressos segundo os indices obtidos no Fibrógrafo, para essa característica. Convém observar que quanto maiores forem estes, menores serão as porcentagens de fibras maduras. Com base nesses dados, aproximados para fins práticos, estabeleceu-se a seguinte escala padrão, para classificação da maturidade: 
Classes de Maturidade

Muito baixa

Baixa

Média

Alta

Muito alta

\section{Valores dos Indices}

Superior a 14,6

14,6-13,4

$13,3-11,8$

$11,7-10,7$

Inferior a 10,7

Na relação a seguir, a mesma escala é apresentada, porém com os valores expressos, de modo aproximado, em porcentagens de fibras maduras, segundo a determinação pelo processo da soda cáustica a $18 \%$. Para comparação, são apresentados os valores correspondentes da escala de classificação adotada pelo Departamento de Agricultura dos Estados Unidos da América.

Classes de

Maturidade

Muito baixa

Baixa

Média

Alta

Muito alta
Método do Fibrógrafo (IAC)

Inferior a 45

45-52

$52,1-63$

$63,1-72$

Superior a 72
Método $\mathrm{NaOH} 18 \%$ (USDA)

Inferior a 60
$60-67$
$68-76$
$77-84$
Superior a 84

A substancial diferença entre as duas escalas demonstra a inconveniência de avaliar a maturidade determinada pelo Fibrógrafo e expressa em termos do método da soda cáustica, com base na escala padrão norte-americana. Com efeito, basta verificar que algodões com maturidade alta, segundo a escala proposta no presente trabalho, poderiam ter essa característica enquadrada na classe baixa, se aquela escala fosse utilizada. Um estudo visando a adaptar os limites de classes da escala norte-americana aos dados utilizados neste trabalho, levaram à determinação dos percentis $1,4,20$ e 60 , na curva da figura 1. Parece nítida a inadequação de tais valores, sobretudo com respeito ao excessivo rigor que se adotaria para situar as fibras analisadas nas classes alta e muito alta.

Os fatos apontados poderiam vir a ser interpretados como decorrentes de um nível geral baixo, quanto à maturidade da fibra, dos algodões utilizados no trabalho de GRIDI-PAPP \& SABINO (1972). Todavia, um exame do mencionado trabalho revela que os materiais empregados abrangiam diferentes espécies de algodoeiro e híbridos intra e interespecíficos, e que, das amostras analisadas, diversas haviam sido produzidas em casa de vegetação, existindo, portanto, condições genéticas e de ambiente para obtenção de fibras com alta maturidade, pelo menos em parte apreciável das amostras. 
QUADRO 1 - Distribuição de freqüências da maturidade da fibra determinada pelo Fibrógrafo Modelo 230 em diferentes genótipos de algodoeiro

Intervalo de classe $\left({ }^{1}\right)$

Freqüência

Observada $\quad$ Esperada $^{(2)}$

$\begin{array}{crr}9-9,9 & 2 & 1,78 \\ 10-10,9 & 5 & 5,71 \\ 11-11,9 & 15 & 12,02 \\ 12-12,9 & 12 & 15,66 \\ 13-13,9 & 17 & 13,35 \\ 14-14,9 & 4 & 7,05 \\ 15-15,9 & 3 & 2,44 \\ 16-16,9 & 1 & 0,53\end{array}$

( ${ }^{1}$ ) Valores expressos em termos da variável $\mathrm{L}^{2} / 10^{6} \mathrm{p}$, conforme determinado no Fibrógrafo. $\left({ }^{2}\right)$ Frequêencias esperadas em função da curva de distribuição normal adaptada aos dados.

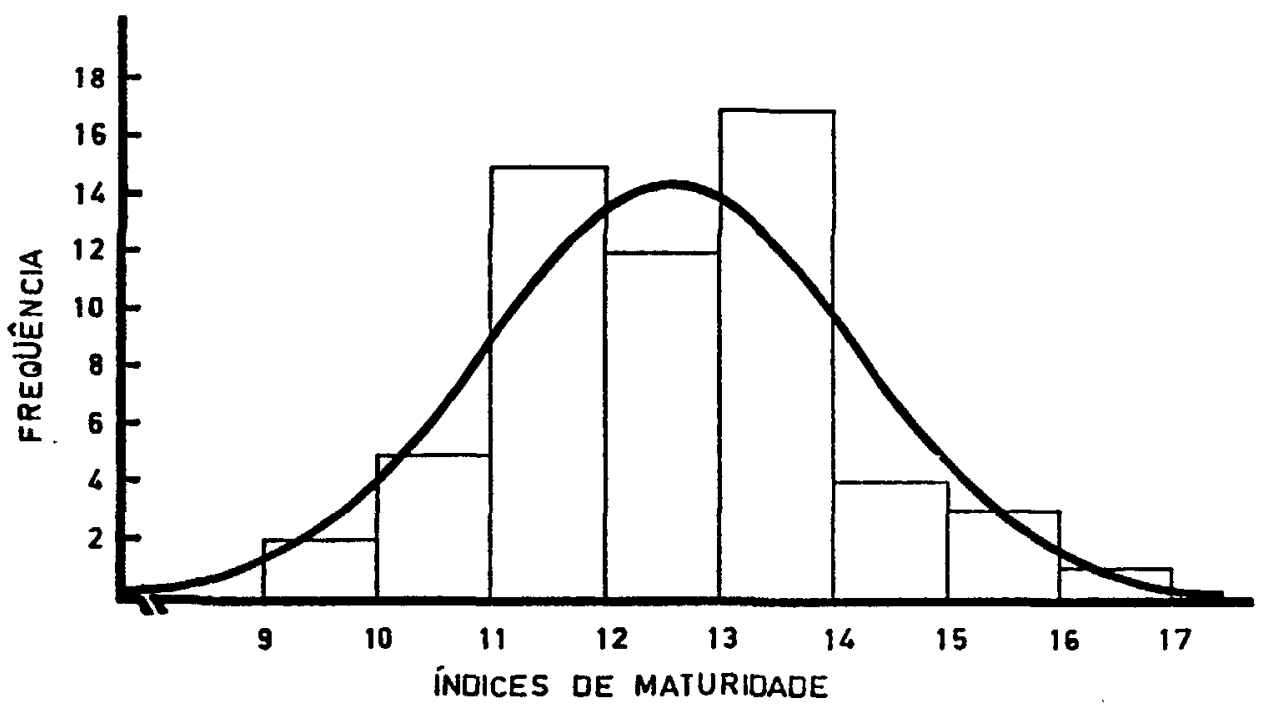

FIGURA 1 - Histograma de freqüências e curva de distribuição normal ajustada a dados de maturidade da fibra do algodoeiro determinada pelo método do Fibrógrafo. 
Descartada, pois, a hipótese de fibras predominantemente imaturas, nos algodões estudados, parece aceitável atribuir os valores relativamente baixos, obtidos no estudo, ao procedimento seguido nas análises, mais especificamente, ao critério excessivamente rigoroso dos analistas, para enquadrar as fibras examinadas na categoria "maduras". De fato, o método da soda cáustica a $18 \%$ consiste basicamente no tratamento das fibras com essa solução e posterior exame, ao microscópio, da forma por elas adotada. Quando assim tratadas, as fibras apresentam contorções, cuja intensidade varia de leve ou pouco definida, para as fibras maduras, até pronunciada, para as imaturas. Entre os extremos há, portanto, certo nivel de contorções que caracteriza fibras de maturidade média. A propósito, lembre-se que, na versão inglesa desse método, as três classes de fibras são identificadas, quando do exame ao microscópio, ao passo que, no procedimento norte-americano, apenas as classes madura e imatura são consideradas, ficando integradas, em uma ou outra delas, as fibras de maturidade média (LORD, 1981). No trabalho de GRIDI-PAPP \& SABINO (1972), foi feita contagem de fibras imaturas e "semimaduras", ou de maturidade média, calculando-se, por diferença, o número de fibras maduras em cada amostra. Provavelmente, ao enquadrar na categoria "semimadura" as fibras para as quais havia dúvidas, introduziuse o critério rigoroso do qual resultaram, no conjunto das amostras estudadas, valores em média baixos para essa característica.

Em última análise, o que importa ressaltar é a necessidade de adotar, na classificação da maturidade determinada pelo Fibrógrafo, uma escala compatível com os dados que deram fundamento ao método. Quer os resultados sejam expressos segundo os valores obtidos no aparelho, quer estejam transformados em porcentagens de fibras maduras, de acordo com o método da soda cáustica, os limites propostos no presente trabalho são adequados para classificação da maturidade do algodão produzido no Brasil, sobretudo na região Centro-Sul.

\section{SUMMARY}

\section{STANDARD CLASSES FOR ASSESSING COTTON FIBER MATURITY DETERMINED BY THE FIBROGRAPH METHOD}

Once the Fibrograph method to determine maturity in cotton fiber was adopted at the Instituto Agronômico (Campinas, State of São Paulo, Brazil), the need of specific standard limits for the several classes of maturity, based on this process, was recognized. In effect, despite of the observed correlation between the results obtained by this method and those revealed by the $\mathrm{NaOH}$ process, which enables one to express the Fibrograph indices in terms of percentages of mature 
fibers, the inadequacy of assessing the results, based on the standard USDA scale for the caustic soda method was soon verified. Actually, if this scale was considered, the great majority of fibers submitted to analysis should be classified as immature. Thus, a study was carried out in order to define a more suitable scale, based on the data originally used to establish the Fibrograph Method. A normal curve $(\bar{x}=12.57$; $s=1.46$ ) was fitted to 59 data of fiber maturity, which includes different genetic materials as well as diverse environmental conditions, comprising, therefore, a broad range of maturity. Due to the goodness of fit $\left(X_{2}=4.57 ; 5 \%=11.07\right)$, the percentiles $10,30,70$ and 90 in the normal curve were chosen and defined as the standard limits, respectively, for the classes "very low", "low", "medium", "high" and "very high" maturity. If Fibrograph indices are to be used to express the results, the limits of such classes were found to be $14.57,13.40,11.79$ and 10.67 , respectively. The correspondent values, if percentages of mature fibers are considered, are, aproximately, $45,52,63$ and $72 \%$.

Index terms: cotton; fiber; maturity; Fibrograph; classification.

\section{REFERENCIAS BIBLIOGRÁFICAS}

GRIDI-PAPP, I.L. \& SABINO, N.P. Maturidade da fibra de algodão determinada por processo óptico - Método do fibrógrafo digital. Revista Brasileira de Tecnologia, São Paulo, 3(2): 99-106, 1972.

LORD, E. Manual of cotton spinning. The characteristics of Raw Cotton. Manchester and London, Butterworth \& Co. Publishers Ltd., The Textile Institute, 1961. v.2, p.1.

The origin and assessment of cotton fibre maturity. Manchester, International Institute for Cotton, 1981. 27p.

SABINO, N.P.; GRIDI-PAPP, I.L. \& LAZZARINI, J.F. Determinação da maturidade da fibra do algodoeiro pelo Fibrógrafo digital. Bragantia, Campinas, 30:I-IV, 1971. (Nota, 1)

; KONDO, J.I. \& CARNEIRO, J.B. Maturidade da fibra de algodão determinada pelo fibrógrafo Modelo 430. Bragantia, Campinas, 39:69-77, 1980. 